\title{
ANALISIS WACANA IKLAN BERBAHASA BANJAR DI SKY RADIO 89.3 FM BANJARMASIN
}

\author{
Kamal Hasuna \\ STKIP PGRI Banjarmasin \\ Jalan Sultan Adam Komplek H. Iyus, No. 18 RT. 23 Banjarmasin, \\ Kalimantan Selatan, Kode pos 70121 \\ email: hkamalhasuna25@gmail.com
}

\begin{abstract}
ABSTRAK
Bahasa merupakan sarana komunikasi dalam masyarakat yang mempunyai peranan dan fungsi penting.Bahasa memiliki fungsi dalam kegiatan masyarakat yaitu sebagai alat komunikasi untuk meyampaikan gagasan, ide, dan pendapat yang menghasilkan suatu variasi.

Penelitian ini berkenaan dengan tindak tutur dalam wacana iklan berbahasa Banjar di SKY radio 89.3 FM Banjarmasin dan bertujuanuntuk: (1) mendeskripsikan bagaimana bentuk tindak tutur dalam wacana iklan berbahasa Banjar di SKY radio 89.3 FM Banjarmasin, (2) mendeskripsikan fungsi tindak tutur dalam wacana iklan berbahasa Banjar di SKY radio 89.3 FM Banjarmasin.

Metode yang digunakan dalam penelitian ini adalah metode kualitatif deskriptif yang berkaitan dengan data yang tidak berupa angka-angka tetapi berupa kualitas bentuk-benuk variabel yang berwujud tuturan sebagai data yang dihasilkan berupa kata-kata tertulis atau lisan tentang sifat-sifat individu, keadaan, gejala, dari kelompok tertentu yang diamati.Sumber data yang digunakan dalam penelitian ini adalah sejumlah naskah iklan yang disiarkan melalui media radio.Berdasarkan hasil penelitian yang diperoleh oleh peneliti, dapat ditarik beberapa kesimpulan. Bentuk tindak tutur yang ditemukan dalam wacana iklan berbahasa Banjar di SKY radio 89.3 FM Banjarmasin, yaitu: a) tindak tutur lokusi, b) tindak tutur ilokusi, dan c) tindak tutur perlokusi. Dari hasil penelitian terdapat empat fungsi tuturan. Fungsi tindak tutur dalam wacana iklan berbahasa Banjar di SKY radio 89.3 FM Banjarmasin, yaitu: a) deklarasi, b) representatif, c) ekspresif, dan d) direktif.
\end{abstract}

Kata Kunci: wacana iklan, bahasa Banjar

\section{PENDAHULUAN}

Manusia selalu melakukan interaksi atau hubungan dengan sesamanya menggunakan bahasa.Bahasa dan manusia merupakan dua hal yang tidak dapat dipisahkan, dalam arti keduanya berhubungan erat. Bahasa merupakan alat komunikasi yang paling penting bagi manusia karena dengan bahasa manusia dapat mengekspresikan apa yang ada dalam pikiran atau gagasannya. Agar komunikasi dapat berlangsung dengan baik, manusia harus menguasai keterampilan berbahasa.

Komunikasi dibagi menjadi dua, yaitu komunikasi secara langsung dan secara tidak langsung, misalnya ceramah, diskusi, dan tanyajawab. Bentuk komunikasi yang digunakan manusia dalam berkomunikasi dapat berupa bahasa lisan maupun tulis.Bahasa lisan dan tulis dapat 
diungkapkan atau diwujudkan dengan menggunakan berbagai sarana. Sarana yang digunakan untuk merealisasikan tuturan tersebut dapat diungkapkan melalui media massa, yakni melalui media elektronik maupun media cetak. Media massa sebagai sarana komunikasi tidak hanya berarti pemberitahuan, namun berarti pula pengumuman, penerangan, penjelasan, penyuluhan, perintah, intruksi, nasehat, ajakan, rayuan, dan sebagainya. Adapun yang melalui media, contoh iklan di televisi, siaran di radio, penulisan opini atau artikel di majalah, surat kabar, dan lain-lain.

Media membantu kelompok dominan menyebarkan gagasannya, mengontrol kelompok lain, dan membentuk consensus antaranggota komunitas (Eriyanto, 2001:36).Komunikasi sebagai alat publikasi tidak bisa lepas dari pengaruh ajaran bahas.Di dalam komunikasi yang wajar dapat diasumsikan bahwa seorang penutur mengartikulasi tuturan dengan maksud untuk mengkomunikasikan sesuatu kepada mitra tuturnya.Iklan merupakan salah satu bentuk komunikasi antara produsen dan konsumen.Tujuan sebuah iklan adalah untuk memperkenalkan dan menawarkan produk.Pada umumnya, iklan dirancang sedemikian rupa untuk menarik perhatian konsumen agar membeli atau menggunakan barang atau jasa yang ditawarkan, maka peran bahasa sangatlah penting. Dengan bahasa yang menarik, indah dan sesuai dengan sasaran yang hendak dicapai akan lebih mudah dimengerti.Dalam kesempatan ini peneliti tertarik memilih SKY Radio 89.3 FM Banjarmasin sebagai objek penelitian.SKY Radio 89.3 FM Banjarmasin yang dijadikan objek penelitian iklan karena di Banjarmasin radio tersebut merupakan salah satu radio swasta terbaik, jangkauannya luas, pendengarnya pun cukup banyak yang sehingga mengundang minat banyak pemasang iklan dalam rangka mengenalkan produk-produknya.

\section{METODE}

Penelitian ini menggunakan pendekatan kualitatif.Pendekatan kualitatif adalah pendekatan yang berkaitan dengan data yang tidak berupa angka-angka tetapi berupa kualitas bentuk-benuk variabel yang berwujud tuturan sebagai data yang dihasilkan berupa kata-kata tertulis atau lisan tentang sifat-sifat individu, keadaan, gejala, dari kelompok tertentu yang diamati (Wardaniah, 2014).Penelitian ini adalah tuturan yang dinyatakan dalam sejumlah naskah iklan di SKY Radio 89.3 FM Banjarmasin yang mengandung tindak tutur lokusi, ilokusi, dan perlokusi. Adapun sumber data dalam penelitian ini adalah sejumlah naskah iklan yang disiarkan melalui media radio. 


\section{HASIL DAN PEMBAHASAN}

\section{A. Bentuk Tindak Tutur Lokusi}

\begin{tabular}{|c|c|c|}
\hline No. Data & Wacana & Makna \\
\hline 1 & Laki-laki :aduh.. aduh yang !! & $\begin{array}{l}\text { Tindak tutur lokusi pada tuturan tersebut } \\
\text { bermakna penutur dalam percakapan } \\
\text { tersebut menginformasikan dirinya } \\
\text { sedang merasa kesakitan. }\end{array}$ \\
\hline 2 & $\begin{array}{l}\text { Laki-laki : anu, satiap malihat pian } \\
\text { gadagupan dada ulun }\end{array}$ & $\begin{array}{l}\text { Tindak tutur lokusi pada tuturan tersebut } \\
\text { bermakna penutur yang merupakan } \\
\text { seorang laki-laki merasa gugup ketika } \\
\text { bertemu dengan mitra tuturnya yang } \\
\text { merupakan seorang perempuan. }\end{array}$ \\
\hline 3 & Perempuan :hmm.. bari muar pian nih & $\begin{array}{l}\text { Tindak tutur lokusi pada tuturan tersebut } \\
\text { bermakna perempuan dalam percakapan } \\
\text { memberitahukan kepada laki-laki yang } \\
\text { menjadi mitra tuturnya bahwa perkataan } \\
\text { laki-laki tersebut membuatnya jengkel. }\end{array}$ \\
\hline 4 & $\begin{array}{l}\text { soalnya mun malihat pipi pian, jadi } \\
\text { handak " } C \text { "!! }\end{array}$ & $\begin{array}{l}\text { Tindak tutur lokusi pada tuturan tersebut } \\
\text { bermakna setiap kali bertemu dan } \\
\text { melihat pipi dari mitra tutur, penutur } \\
\text { memiliki keinginan untuk "C" yang } \\
\text { merupakan kata rayuan berarti ingin } \\
\text { mencium. }\end{array}$ \\
\hline 5 & $\begin{array}{l}\text { Laki-laki: pian jua! banyak banar } \\
\text { lombok nang dimakan, sakit parut tuh } \\
\text { biasanya jadi awal diare }\end{array}$ & $\begin{array}{l}\text { Tindak tutur lokusi pada tuturan tersebut } \\
\text { bermakna penutur menginformasikan } \\
\text { mengkonsumsi cabai terlalu berlebihan } \\
\text { dapat memicu gejala diare yang diawali } \\
\text { dengan sakit perut. }\end{array}$ \\
\hline 6 & $\begin{array}{l}\text { narasi :amun sakit parut minumi } \\
\text { entrostop! }\end{array}$ & $\begin{array}{l}\text { Tindak tutur lokusi pada tuturan tersebut } \\
\text { bermakna jika sakit perut pastikan } \\
\text { mengkonsumsi obat diare dengan merek } \\
\text { entrostop. }\end{array}$ \\
\hline 7 & $\begin{array}{l}\text { Sales: ngini, ulun handak } \\
\text { manawarkan produk minyak angin } \\
\text { aroma terapi }\end{array}$ & $\begin{array}{l}\text { Tindak tutur lokusi pada tuturan tersebut } \\
\text { bermakna penutur yang merupakan } \\
\text { seorang sales atau penjual berusaha } \\
\text { menawarkan barang berupa minyak } \\
\text { angin aroma terapi kepada seorang calon } \\
\text { pembeli. }\end{array}$ \\
\hline 8 & $\begin{array}{l}\text { Perempuan1: bujur banar.. kalo } \\
\text { pusing, pegal, atau rasa kada nyaman } \\
\text { awak tinggal oles, emm hangat }\end{array}$ & $\begin{array}{l}\text { Tindak tutur lokusi pada tuturan tersebut } \\
\text { bermakna jika merasa pusing, pegal atau } \\
\text { merasa tidak enak badan jangan gunakan } \\
\text { produk minyak angin aroma terapi } \\
\text { merek freshcaredengan cara dioles } \\
\text { dibagian yang dirasa perlu. }\end{array}$ \\
\hline
\end{tabular}




\begin{tabular}{|c|l|l|}
\hline 9 & $\begin{array}{l}\text { Pembeli1: ini nah aku mancari } \\
\text { dongkrak buaya }\end{array}$ & $\begin{array}{l}\text { Tindak tutur lokusi pada tuturan tersebut } \\
\text { bermakna penutur menginformasikan } \\
\text { sedang mencari dongkrak buaya yang } \\
\text { ditujukan kepada penjual. }\end{array}$ \\
\hline 10 & $\begin{array}{l}\text { Mixagrip rhema atasi pegal linu kada } \\
\text { balawasan, baca aturan pakai amun } \\
\text { sakit tatarusan hubungi dokter. }\end{array}$ & $\begin{array}{l}\text { Tindak tutur lokusi pada tuturan tersebut } \\
\text { bermakna Mixagrip rhemadapat } \\
\text { meredakan rasa pegal dalam waktu yang } \\
\text { singkat, penutur juga meminta mitra } \\
\text { tutur (pendengar) membaca aturan pakai } \\
\text { minum obat dan menghubungi dokter } \\
\text { jika sakit yang dialami tidak mendapat } \\
\text { perubahan setelah mengkonsumsi obat } \\
\text { tersebut. }\end{array}$ \\
\hline
\end{tabular}

\section{B. Tindak Tutur Ilokusi pada Wacana Iklan Berbahasa Banjar di SKY Radio 89.3 FM Banjarmasin}

\begin{tabular}{|c|c|c|}
\hline No. Data & Wacana & Makna \\
\hline 1 & $\begin{array}{l}\text { Laki-laki: soalnya mun malihat pipi } \\
\text { pian, jadi handak “ } C \text { ”!! }\end{array}$ & $\begin{array}{l}\text { Tindak tutur ilokusi pada tuturan } \\
\text { tersebut bermakna penutur ingin } \\
\text { mencium mitra tuturnya setiap kali } \\
\text { bertemu dan melihat pipi dari mitra } \\
\text { tutur, penutur memiliki keinginan untuk } \\
\text { "C" yang merupakan perwakilan dari } \\
\text { kata cium sebagai kata-kata rayuan. }\end{array}$ \\
\hline 2 & $\begin{array}{l}\text { Perempuan: pian jua kada } \\
\text { manukarakan ulun entrostop, lakasi } \\
\text { tukarakan sakit parut!! }\end{array}$ & $\begin{array}{l}\text { Tindak tutur ilokusi pada tuturan } \\
\text { tersebut bermakna penutur meminta } \\
\text { mitra tutur untuk membelikannya obat } \\
\text { entrostop, penutur juga memerintahkan } \\
\text { agar mitra tutur membeli obat tersebut } \\
\text { dengan cepat karna sudah merasa sakit } \\
\text { perut. }\end{array}$ \\
\hline 3 & $\begin{array}{l}\text { Sales: inggih ibu tapi nangini kada } \\
\text { kalah jua mutunya }\end{array}$ & $\begin{array}{l}\text { Tindak tutur lokusi pada tuturan tersebut } \\
\text { bermakna penutur menginginkan } \\
\text { pembeli membeli produk bermutu dan } \\
\text { produk minyak angin aroma terapi yang } \\
\text { ditawarkan memiliki mutu yang dapat } \\
\text { bersaing dengan merek yang dimaksud } \\
\text { ibu (calon pembeli), dan mengharapkan } \\
\text { ibu mau membeli minyak angin aroma } \\
\text { terapi tersebut. }\end{array}$ \\
\hline 4 & $\begin{array}{l}\text { Laki-laki1: eeeeh eeeh eeeh } \\
\text { ehhh..freshcare anggit siapa ini } \\
\text { katinggalan? }\end{array}$ & $\begin{array}{l}\text { Tindak tutur ilokusi pada tuturan } \\
\text { tersebut bermakna penutur bertanya } \\
\text { kepada rekan-rekannya, apakah diantara } \\
\text { mitra tuturnya mengalami kehilangan } \\
\text { barang berupa minyak angin aroma } \\
\text { terapi dengan merek freshcaredan }\end{array}$ \\
\hline
\end{tabular}




\begin{tabular}{|c|c|c|}
\hline & & $\begin{array}{l}\text { mengharapkan } \quad \text { rekan-rekannya } \\
\text { memeriksa barang masing-masing. }\end{array}$ \\
\hline 5 & $\begin{array}{l}\text { Perempuan1: Freshcare ulun masih } \\
\text { ada pang, anggit pian lainan lah? }\end{array}$ & $\begin{array}{l}\text { Tindak tutur ilokusi pada tuturan } \\
\text { tersebut bermakna penutur } \\
\text { menginformasikan bahwa freshcare } \\
\text { miliknya masih ada dan tidak hilang, } \\
\text { kemuadian meminta rekan yang lain } \\
\text { untuk memeriksa barang bawaannya } \\
\text { memastikan apakah freshcarenya } \\
\text { tertinggal. }\end{array}$ \\
\hline 6 & $\begin{array}{l}\text { Perempuan1: wah pakai freshcare jua } \\
\text { kah ka? }\end{array}$ & $\begin{array}{l}\text { Tindak tutur ilokusi pada tuturan } \\
\text { tersebut bermakna penutur bertanya } \\
\text { apakah mitra tutur juga menggunakan } \\
\text { minyak angin aroma terapi yang sama } \\
\text { dan berharap mitra tutur memberikan } \\
\text { jawaban. }\end{array}$ \\
\hline 7 & $\begin{array}{l}\text { Perempuan1: bujur banar.. kalo } \\
\text { pusing, pegal, atau rasa kada nyaman } \\
\text { awak tinggal oles, emm hangat }\end{array}$ & $\begin{array}{l}\text { Tindak tutur ilokusi pada tuturan } \\
\text { tersebut bermakna perempuan1 sebagai } \\
\text { penutur menyarankan } \\
\text { menggunakan freshcaredengan cara } \\
\text { dioles jika mengalami pusing, pegal, } \\
\text { atau tidak enak badan. }\end{array}$ \\
\hline 8 & $\begin{array}{l}\text { Penjual: salamat kamarian, ada yang } \\
\text { kawa ulun bantu? }\end{array}$ & $\begin{array}{l}\text { Tindak tutur ilokusi pada tuturan } \\
\text { tersebut maknanya penutur bertanya } \\
\text { kepada pembeli sebagai mitra tutur } \\
\text { apakah ada yang bisa penutur lakukan } \\
\text { sebagai penjual untuk melayani pembeli. }\end{array}$ \\
\hline 9 & $\begin{array}{l}\text { Penjual: maaf cil maaf man, sabuting } \\
\text { sabuting lah }\end{array}$ & $\begin{array}{l}\text { Tindak tutur ilokusi pada tuturan } \\
\text { tersebut bermakna penutur mengusulkan } \\
\text { agar pembeli yang terdiri dari laki-laki } \\
\text { dan perempuan untuk tertib bergantian } \\
\text { menyebutkan keperluan yang sedang } \\
\text { mereka cari agar dapat memudahkan } \\
\text { proses jual beli. }\end{array}$ \\
\hline 10 & $\begin{array}{l}\text { Penjual:ini man kunci inggrisnya, } \\
\text { nang ini buatan Jerman nang } \\
\text { sabutingnya ulahan Taiwan }\end{array}$ & $\begin{array}{l}\text { Tindak tutur ilokusi pada tuturan } \\
\text { tersebut bermakna penutur menunjukan } \\
\text { barang berupa kunci inggris yang ingin } \\
\text { dibeli pembeli sudah diambilkan, } \\
\text { kemudian menginformasikan ada dua } \\
\text { buah kunci inggris masing-masing } \\
\text { produksi Negara Jerman dan Negara } \\
\text { Taiwan, dan mengharapkan pembeli } \\
\text { memilih kunci inggris produksi Negara } \\
\text { mana yang ingin dibeli. }\end{array}$ \\
\hline
\end{tabular}




\section{Tindak Tutur Perlokusi pada Wacana Iklan Berbahasa Banjar di SKY Radio 89.3 FM Banjarmasin}

\begin{tabular}{|c|c|c|}
\hline $\begin{array}{l}\text { No. } \\
\text { Data }\end{array}$ & Wacana & Makna \\
\hline 1 & Laki-laki :aduh.. aduh yang !! & $\begin{array}{l}\text { Tindak tutur perlokusi pada tuturan } \\
\text { tersebut penutur berusaha menarik } \\
\text { perhatian mitra tutur dengan cara } \\
\text { mengeluh kesakitan, efek yang } \\
\text { dihasilkan mitra tutur menjadi khawatir. }\end{array}$ \\
\hline 2 & Perempuan: hmm.. bari muar pian nih & $\begin{array}{l}\text { Tindak tutur perlokusi pada tuturan } \\
\text { tersebut penutur berusaha } \\
\text { menyenangkan mitra tutur atas rayuan } \\
\text { yang dilakukan, efek yang dihasilkan } \\
\text { mitra tutur menjadi senang. }\end{array}$ \\
\hline 3 & $\begin{array}{l}\text { Laki-laki: pian jua! banyak banar } \\
\text { lombok nang dimakan, sakit parut tuh } \\
\text { biasanya jadi awal diare, seharusnya } \\
\text { pas sakit parut minum satu tablet } \\
\text { entrostop, serap racunnya, stop } \\
\text { mulesnya, kada meolah sembelit. }\end{array}$ & $\begin{array}{l}\text { Tindak tutur perlokusi pada tuturan } \\
\text { tersebut penutur berusaha melegakan } \\
\text { mitra tutur karna gejala awal diare yang } \\
\text { diderita ada obatnya, efek yang } \\
\text { diharapkan mitra tutur menjadi senang. }\end{array}$ \\
\hline 4 & $\begin{array}{l}\text { Perempuan: pian jua kada } \\
\text { manukarakan ulun entrostop, lakasi } \\
\text { tukarakan sakit parut!! }\end{array}$ & $\begin{array}{l}\text { Tindak tutur perlokusi pada tuturan } \\
\text { tersebut bermakna penutur membujuk } \\
\text { mitra tutur untuk membelikan obat } \\
\text { entrostop, efek yang diharapkan mitra } \\
\text { tutur menjadi takut dengan ancaman } \\
\text { yang dilakukan penutur pada tuturan } \\
\text { sebelumnya yang mengatakan akan } \\
\text { membuat mitra tutur menjadi bincul atau } \\
\text { benjol. }\end{array}$ \\
\hline 5 & $\begin{array}{l}\text { Sales: ngini, ulun handak } \\
\text { manawarkan produk minyak angin } \\
\text { aroma terapi }\end{array}$ & $\begin{array}{l}\text { Tindak tutur perlokusi pada tuturan } \\
\text { tersebut bermakna penutur yang } \\
\text { merupakan seorang sales atau penjual } \\
\text { menarik perhatian calon pembeli sebagai } \\
\text { mitra tutur untuk mendengarkan } \\
\text { penawaran produk berupa minyak angin } \\
\text { aroma terapi yang sedang dipasarkan, } \\
\text { efek yang diharapkan mitra tutur } \\
\text { menjadi penasaran tentang produk apa } \\
\text { yang sedang ditawarkan. }\end{array}$ \\
\hline 6 & $\begin{array}{l}\text { Penjual : maaf cil maaf man, sabuting } \\
\text { sabuting lah }\end{array}$ & $\begin{array}{l}\text { Tindak tutur perlokusi pada tuturan } \\
\text { diatas penutur memerintahkan agar } \\
\text { pembeli selaku mitra tutur untuk }\end{array}$ \\
\hline
\end{tabular}




\begin{tabular}{|l|l|l|}
\hline & $\begin{array}{l}\text { berbicara secara bergantian, efek yang } \\
\text { diharapkan mitra tutur untuk } \\
\text { memaklumi situasi proses jual beli. }\end{array}$ \\
\hline
\end{tabular}

\section{Fungsi tindak tutur}

Dalam wacana iklan yang ada di SKY Radio 89.3 FM Banjarmasin ditemukan Fungsi tindak tutur yang terdiri deklarasi, representatif, ekspresif, direktif, dan komisif.

\begin{tabular}{|c|c|c|}
\hline $\begin{array}{c}\text { Fungsi Tidak } \\
\text { Tutur }\end{array}$ & Wacana & Makna \\
\hline Deklarasi & $\begin{array}{l}\text { Penjual: hadang lah setumat ulun } \\
\text { ambilakan }\end{array}$ & $\begin{array}{l}\text { Tuturan diatas termasuk tuturan } \\
\text { deklarasi, karena tuturan tersebut } \\
\text { merupakan tuturan mengabulkan. } \\
\text { Dalam tuturan ini penutur } \\
\text { mengabulkan permintaan mitra tutur } \\
\text { untuk membeli sesuatu dan akan } \\
\text { segera diambilkan oleh penutur. }\end{array}$ \\
\hline Representatif & $\begin{array}{l}\text { Ibu: itu ding, minyak angin aroma } \\
\text { terapi nang berkualitas yaa } \\
\text { freshcare haja }\end{array}$ & $\begin{array}{l}\text { Tuturan diatas termasuk tuturan } \\
\text { representatif, sebab berisi informasi } \\
\text { yang penuturnya terikat oleh } \\
\text { kebenaran isi tuturan tersebut. Penutur } \\
\text { bertanggung jawab bahwa tuturan } \\
\text { yang diucapkan itu memang fakta dan } \\
\text { dapat dibuktikan bahwa freshcare } \\
\text { adalah produk minyak angin aroma } \\
\text { terapi dengan kualitas terbaik. Tuturan } \\
\text { itulah yang mengikat penuturnya akan } \\
\text { kebenaran terhadap apa yang } \\
\text { diucapkannya. }\end{array}$ \\
\hline Ekspresif & Laki-laki :aduh.. aduh yang !! & $\begin{array}{l}\text { Tuturan diatas termasuk fungsi tindak } \\
\text { tutur ekspresif, karena tuturan tersebut } \\
\text { dapat diartikan sebagai tuturan basa- } \\
\text { basi yang dilakukan penutur untuk } \\
\text { mendapat perhatian dari mitra tutur } \\
\text { melalui ekspresi penutur } \\
\text { mengucapkan kata aduh yang } \\
\text { dilakukan dalam tuturan merupakan } \\
\text { ekspresi penutur saat itu. }\end{array}$ \\
\hline Direktif & $\begin{array}{l}\text { Perempuan: pian jua kada } \\
\text { manukarakan ulun entrostop, lakasi } \\
\text { tukarakan sakit parut!! }\end{array}$ & $\begin{array}{l}\text { Tuturan disamping mengilustrasikan } \\
\text { adanya tindak tutur direktif dalam } \\
\text { wujud perintah. Perintah dilakukan } \\
\text { oleh penutur kepada mitra tutur untuk } \\
\text { membelikan obat entrostop. }\end{array}$ \\
\hline
\end{tabular}


Berdasarkan hasil penelitian, dapat dikatakan bahwa dalam wacana iklan berbahasa banjar di SKY Radio 89.3 FM Banjarmasin terdapat tiga bentuk tindak tutur, yang terdiri dari tindak tutur lokusi, tindak tutur ilokusi, dan tindak tutur perlokusi. Hal ini dapat menjelaskan bahwa pada wacanaiklan berbahasa banjar di SKY Radio 89.3 FM Banjarmasin mengandung banyak bentuk tindak tutur, dan dalam hal ini tindak tutur lokusi, ilokusi, dan perlokusi sama banyak digunakan, karena dalam ketiga bentuk tindak tutur tersebut mengandung bentuk pernyataan, permintaan atau ajakan, dan memberikan pengaruh terhadap mitra tutur sebagai pendengar. Banyaknya tindak tutur lokusi yang ditemukan pada wacana iklan berbahasa banjar di SKY Radio 89.3 FM Banjarmasin karenatindak tutur lokusi adalah tindak tutur yang menyatakan sesuatu dalam arti "berkata" atau tindak tutur dalam bentuk kalimat yang bermakna dan dapat dipahami.Dalam wacana iklan berbahasa banjar di SKY Radio 89.3 FM Banjarmasin juga terdapat banyak tindak tutur lokusi karena tindak tutur ilokusi ialah tuturan yang mengandung makna sebenarnya.Beberapa verbal yang menandai tindak tutur ilokusi, yakni, mengucapkan selamat, bertanya, menyarankan, berterima kasih, mengusulkan, mengakui, berjanji, mendesak, dan sebagainya. Selain tindak tutur lokusi dan ilokusi juga ditemukan banyak tindak tutur perlokusi yaitutindak tutur yang berkenaan dengan adanya ucapan orang lain sehubungan dengan sikap dan perilaku non-linguistik dari orang lain itu, ada beberapa verba yang memadai tindak tutur perlokusi, antara lain, membujuk, menipu, mendorong, membuat jengkel, menakut nakuti, menyenangkan, melegakan, mempermalukan, menarik perhatian, dan sebagainya.

Selain bentuk tindak tutur, dari hasil penelitian juga terdapat empat fungsi tuturan, yakni deklarasi, representatif, ekspresif, dan direktif. dan dalam hal ini teranalisis banyak fungsi tuturan ekspresif, karena dalam tindak tutur ekspresif kalimat-kalimat yang diutarakan mengekspresikan keadaan-keadaan psikologis dan dapat berupa pernyataan-pernyatan rasa senang, sedih, suka, tidak suka, gembira atau duka yang digunakan untuk menarik minat pembeli terhadap produk yang di iklankan. Dari empat fungsi tindak tutur yang ditemukan paling sedikit fungsi tindak tutur deklarasi, karena dalam wacana iklan berbahasa banjar di SKY Radio 89.3 FM Banjarmasin lebih banyak ditemukan bentuk permintaan dibanding fungsi mengabulkan, karena tindak tutur deklarasi meliputi tuturann memutuskan, membatalkan, melarang, mengijinkan, member maaf, mengesahkan, mengabulkan, dan mengampuni. 


\section{SIMPULAN}

a. Pada iklan wacana berbahasa banjar di SKY Radio 89.3 FM Banjarmasin mengandung banyak bentuk tindak tutur, dan dalam hal ini tindak tutur lokusi, ilokusi, dan perlokusi sama banyak digunakan, karena dalam ketiga bentuk tindak tutur tersebut mengandung bentuk pernyataan, permintaan atau ajakan, dan memberikan pengaruh terhadap mitra tutur sebagai pendengar.

b. Dari hasil penelitian terdapat empat fungsi tuturan, yakni deklarasi, representatif, ekspresif, dan direktif. dan dalam hal ini teranalisis banyak fungsi tuturan ekspresif, karena dalam tindak tutur ekspresif kalimat-kalimat yang diutarakan mengekspresikan keadaan-keadaan psikologis dan dapat berupa pernyataan-pernyatan rasa senang, sedih, suka, tidak suka, gembira atau duka yang digunakan untuk menarik minat pembeli terhadap produk yang di iklankan.

\section{SARAN}

Berdasarkan simpulan penelitian yang dikemukakan, maka perlu diajukan saran sebagai berikut:

a. Bagi pembaca dapat dijadikan sebagai salah satu alternatif sumber referensi, wawasan untuk membatu menambah pemahaman mengenai tindak tutur yang berkenaan dengan kajian pragmatik dalam iklan media massa lokal dengan objek penelitian iklan radio yang menggunakan bahasa Banjar.

b. Bagi peneliti selanjutnya yang berminat pada bidang kajian yang sama, diharapkan dapat melengkapi penelitian yang telah dilakukan secara lebih lengkap dan mendalam.

\section{DAFTAR RUJUKAN}

Chaer, A. dan Leonie, A. 2010. Sosiolinguistik: Perkenalan Awal. Jakarta: Rineka Cipta.

Chaer, A. 2010. Linguistik Umum: Edisi Baru. Jakarta: Rineka Cipta.

Chaer, A. 2009. Psikolinguistik: kajian teoritik. Jakarta: Rineka Cipta.

Departemen Pendidikan Nasional. 2013. Kamus Besar Bahasa Indonesia. Jakarta: PT Gramedia Pustaka Utama. Cetakan Ketujuh Edisi Keempat.

Eriyanto. 2001. Analisis Wacana: Pengantar analisis teks media. Yogyakarta.

Hapip, A. D. 2008. Kamus Banjar Indonesia.Cetakan Keenam. Banjarmasin: Rahmat Hafiz Al Mubaraq. 
Kawi, D. 2011. Telaah Bahasa Banjar.Banjarbaru: Cripta Cendekia.

Rustono. 2000. Implikatur Tuturan Humor. Semarang: CV IKIP SEMARANG PRESS.

Wardaniah. 2014. Tindak Tutur dalam Slogan Wacana Politik di Kota Tanjung Kabupaten Tabalong.Skripsi tidak diterbitkan. Banjarmasin: STKIP PGRI Banjarmasin.

Yule, G. 2006. Pragmatik. Banjarmasin, Kalimantan Selatan: PBS FKIP Universitas Lambung Mangkurat.

Zamzani. 2007. Kajian Sosiopragmatik. Yogyakarta: Cipta Pustaka. 